\title{
Strategies of ecological restoration based on the processes of
}

\section{ecological degradation}

\author{
Mei-rong Tian ${ }^{1, a}$, Ji-xi Gao ${ }^{1, b}$, Zhao-ping Yang ${ }^{2, c}$
} 1Nanjing Institute of Environmental Science, Ministry of Environmental Protection, Nanjing
210042,China.

2 Jiangsu Key Laboratory of Atmospheric Environment Monitoring and Pollution Control, School of Environmental Science and Engineering, Nanjing University of Information Science \& Technology, Nanjing 210044

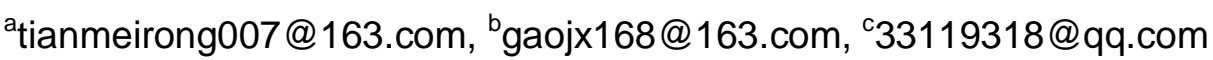

\section{Key words: Ecological degradation; Degradation process; Ecological restoration}

Abstract: The ecological degradation have been aggravated under the background of global climate change and increasing social-economic development. It is important to ascertain the process and mechanism of ecological degradation, which is considered prerequisite of choosing effective restoration measures. This paper further discussed and clarified the degradation mechanism in terms of retrogressive succession, aviation from natural state and impairing mechanism of the ecosystem. According to the differences in speed and tendency, the degradation processes was classified into four categories including ecological "mutation", "jump", "gradient" and "pulse" and the characteristics were then analyzed, and followed by the analysis, it was put forward that different restoration methods including ecological rehabilitation, restoration, recovery or comprehensive methods should be applied respectively. It was then concluded that the ecological restoration should aim at improving the function of ecosystem, which is the inevitable trend for ecological restoration studies.

\section{Introduction}

Ecological degradation, which is considered to be one of the most severe environmental challenges in the world [1], reflects the combined effects by ecological matrix, internal motive actors and external disturbance. Therefore, it is important to ascertain the driving factors, process and mechanism of ecological degradation, which has been becoming the key step of improving restoration effects. With the continuous attention as well as the development of restoration technologies, ecological restoration has been included in some large scale programmes such as Strategic Plan for the U.S. Biosphere Reserve Program, International Geosphere-Biosphere Program(IGBP), and International Human Dimensions Programme on Global Environmental Change(IHDP), and certain experiences have been accumulated in terms of vegetation recover in desertification land, comprehensive treatment for water and soil loss, vegetation recover in degraded grassland, ecological restoration in mining area, and the selection of suitable restoration species[2,3,4].

However, the restoration of degraded ecosystem is an extremely slow process, and academic disputes still exist on fundamental level, for example, the confusion among the concepts of ecological restoration, recover and reconstruction is affecting the development of the discipline, leading to uncertain and impractical restoration targets. Meanwhile, due to the lack of quantity 
evaluation standards and affected by local economic development and management measures [5], most restoration projects are considered to have relatively low benefits [6]. In this article, we discuss the practical meaningness of ecological degradation in terms of succession process, deviation mechanism and damage rationale, and try to clarify the similarities and differences among the concepts of ecological restoration, recover and reconstruction, and explore the timeliness and effectiveness for restoration objectives in different degradation processes.

\section{Mechanism of ecological degradation}

Ecological degradation is an external disturbed process in wich the structure and functions of the ecosystem are damaged, retrogressive succession deviated from natural state occurs and the spontaneous recovery resilience reduces or loses.

Retrogressive succession. From the aspect of ecosystem succession, ecological degradation is a ecological process of retrogressive succession [7]. When the external disturbance is strong enough to exceed the threshold of the ecosystem, the resilience will be impaired and the structure and functions will change, and the ecosystem will deviate from top-level and succeed to degradation state [8].

Deviation from natural state. Degradation state is totally different with the natural one. With the increasing external disturbance, ecosystem will deviate from the previous development track, leading to the change of structure, process and functions, and then the bio-diversity will decrease, energy flow and information exchange will be disturbed, the bio-productivity will decrease and the mutual relationship between the living beings will also change[9].

Damage of structure and functions. From the aspect of damage to the ecosystem, due to external disturbance, ecosystem will go against sustainable development [10], structure and functions will be impaired, stability will decrease, the capability of anti-disturbance will also reduce. Ecosystem will gradually degrade and even vanish without manual intervened ecological restoration.

\section{Process of ecological degradation}

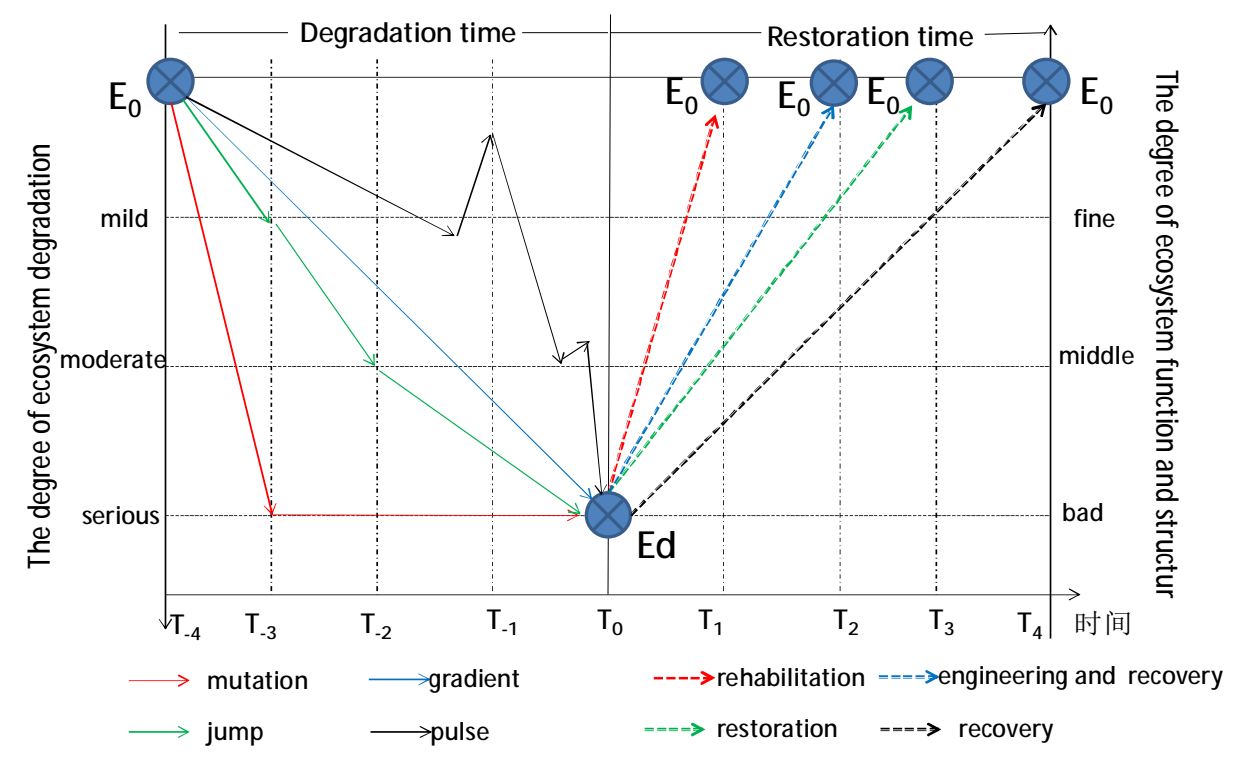

Fig. 1 The relationship of Time between different Degradation types and Ecological Restoration

Note: Time axis indicates the relative duration, $T_{0}$ current state for restoration, $T_{1}, T_{2}, T_{3}$, Future state for restoration; $T_{-1} 、 T_{-2}$ 、 $T_{-3} 、 T_{-4}$ Relative time state for degradation, $E_{d}$ and $T_{0}$ indicates the current degraded ecosystem, $E_{1} 、 E_{2} 、 E_{3} 、 E_{4}$ is the state of ecosystem in $T_{1}, T_{2} 、 T_{3} 、 T_{4}$ respectively, in which $E_{0}$ means ungraded ecosystem. 
Due to differences of the external pressures and the resisting capacity of the ecosystem, ecological degradation, which is different in speed and process, represents different characteristics in terms of retrogressive succession, deviation from natural state and damage to structure and functions. According to the differences in speed and tendency, the degradation processes can be classified into four categories including ecological "mutation", "jump", "gradient" and "pulse" (Fig.1).

Characteristics of different ecological succession processes, deviation mechanism and damage rationale are summarize (Table 1).

Table1 Ecological degradation characteristics of different ecological degradation process

\begin{tabular}{|c|c|c|c|}
\hline & Succession processes & Deviation mechanism & Damage rationale \\
\hline "Mutation" & $\begin{array}{l}\text { Destructive retrogressive } \\
\text { succession, irreversible }\end{array}$ & $\begin{array}{l}\text { Deviates from original state at high } \\
\text { speed, need rehabilitation }\end{array}$ & $\begin{array}{l}\text { Severe damage, strong disturbance } \\
\text { lead to severe degradation in } \\
\text { initial stage }\end{array}$ \\
\hline "Jump" & $\begin{array}{l}\text { Between "mutation" and "gradient", } \\
\text { with increasing disturbance and } \\
\text { degradation }\end{array}$ & $\begin{array}{l}\text { Deviates from original state at } \\
\text { increasing speed under increasing } \\
\text { disturbance and degradation }\end{array}$ & $\begin{array}{l}\text { Severe damage, with increasing } \\
\text { degradation }\end{array}$ \\
\hline "Gradient" & $\begin{array}{l}\text { Gradual retrogressive succession, } \\
\text { the disturbance and degradation } \\
\text { are almost constant }\end{array}$ & $\begin{array}{l}\text { Deviates from original state at } \\
\text { constant speed, ecosystem can be } \\
\text { restored } \quad \text { without external } \\
\text { disturbance. }\end{array}$ & Increasing damage and degradation \\
\hline "Pulse" & $\begin{array}{l}\text { Alternative positive and } \\
\text { retrogressive succession, but it is } \\
\text { degradation in total }\end{array}$ & $\begin{array}{l}\text { Fluctuates from original state due } \\
\text { to discontinuous disturbance }\end{array}$ & $\begin{array}{l}\text { Damage is light or severe according } \\
\text { to the disturbance; degrades when } \\
\text { disturbance exists, and recovers } \\
\text { when disturbances disappear }\end{array}$ \\
\hline
\end{tabular}

\section{Strategies of ecological restoration under different processes of ecological degradation}

Ecological rehabilitation under the "mutation" process. The mutation process will lead to severe damage to ecosystem, and the extent of the degradation is far beyond its own resilience ability, therefore, manual measures must be applied to rehabilitate the ecosystem. This kind of process include the vegetation degradation caused by debris flow and volcano eruption as well as the ecological degradation caused by mining process [10], etc. Ecological rehabilitation refers to a process in which certain technologies and methods will be applied to control the dominant degradation fators and the progress manually and the internal/external information, energy and material flows will be optimized based on ecological principles in order to repair the ecosystem [11]. The duration $\left(\mathrm{T}_{0}-\mathrm{T}_{1}\right)$ for ecological rehabilitation is relatively short, but the need for human and financial resources as well as the maintenance cost are high, since the ecosystem has severely damaged and manual intervention is inevitable.

Ecological recovery under the "pulse" process. The "pulse" process is caused by discontinuous external disturbance, which has different effects on the ecosystem. The degradation is determined by the strength of the disturbance when it exists and the ecosystem will recover itself when the disturbance disappear. Therefore, the ecosystem has relatively strong ability to recover and improve its functions. It is underlined that ecological recovery is a natural and integrated process which will recover the ecosystem to an ideal state [12]. The preconditions for conducting ecological recovery is that the structure and functions of the ecosystem do not have fundamental change under the external disturbance and the degradation is slight enough to be recovered by its own resilience. Therefore, ecological recovery will not depends on manual intervention but the strength of nature 
itself. Ecological recovery needs the longest time $\left(\mathrm{T}_{0}-\mathrm{T}_{4}\right)$ but the least cost, it depends on the own resilience of nature, but requires that the external disturbance should be controlled in the recovery process.

Ecological engineering restoration based on "jump" process. In the "jump" process, the degradation is accelerated due to increasing ecological pressure, the ecosystem is severely damaged and deviated from original state, therefore, manual measures are necessary for restoration. Ecological engineering restoration is to apply manual intervention measures in the restoration process in order to reduce the natural restoration time and facilitate the sound development of the ecosystem [13]. Biological restoration measures are commonly adopted and engineering technologies will be used to provide real time protection for the ecosystem [14]. For example, eco-hydrological engineering should be conducted to manage the ecological degradation caused by the construction of large-scale water resources and hydropower projects. Ecological engineering restoration needs longer time $\left(\mathrm{T}_{0}-\mathrm{T}_{2}\right)$ and more cost than ecological re-construction, and it is difficult to restore the ecosystem without manual intervention.

Ecological comprehensive restoration based on "gradient" process. The "gradient" process indicates that ecosystem gradually degrades due to continuous external pressure and it is impossible to rely on resilience to recover, therefore, manual intervention (ecological engineering) is necessary to achieve the restoration objectives. For instance, in case of farmland reclaim from mountain or lake, the degradation of native ecosystem has to be restored by manual intervention measures including returning farmland to grassland or lake. Ecological comprehensive restoration, which integrates engineering restoration and natural recover, requires longer time $\left(\mathrm{T}_{0}-\mathrm{T}_{3}\right)$ than ecological engineering restoration. In the first stage, manual intervention measures are adopted and then the ecosystem will recover to natural state via its own resilience.

\section{Discussion}

Clear objectives will be fundamental in defining the process of ecological restoration. Though most scholars think that the objective should be restoring original state or increasing bio-diversity or achieving health state of the ecosystem. We believe that the final purpose of ecological restoration is to fully develop the functions of the ecosystem, and it is not considered to be successful restoration if only the structure and composition are rebuilt, without the repair of functions $[15,16]$. Therefore, the objective of ecological restoration is to repair the functions of ecosystem and construct logical structure; based on different degradation processes, different protection targets should be set up in order to determine and apply the detailed measures.

Benefit evaluation, which is an important part for ecological restoration study, includes evaluation on both natural system and socio-economic system. It is recommended to add dynamic evaluation mechanism in constructing the index system and evaluate the cost of the restoration strategies. The effects of ecological restoration should be evaluated on process-cost-benefit perspectives and provide scientific basis for equitable fund distribution. We believe that indices and standards of benefit evaluation for ecological restoration will be key points in the future study.

\section{Acknowledgements}

This work was financially supported by the National Environmental Conservation Research Program (Grant No.201409055). 


\section{References}

[1] Zhaoping Yang, Jixi Gao, Kexing Zhou, et al. Evaluation of ecological restoration: research progress.Chinese Journal of Ecology, 2013,32( 9) : 2494-2501.(in Chinese)

[2] Grant AS, Nelson CR, Switalski TA, et al. Restoration of native plant communities after road decommissioning in the Rocky Mountains: Effect of seed-mix composition on vegetative establishment restoration. Ecology, 2011, 19: 160-169.

[3] Gaynor V. 1990. Prairie restoration on a corporate site. Restoration and Reclamation Review, 1: 35-40.

[4] Mansfield B, Towns D. 1997. Lessons of the Islands: Restoration in New Zealand. Restoration and Management Notes, 15: 150-154.

[5] Choi YD. 2004. Theories for ecological restoration in changing environment: Toward 'futuristic' restoration. Ecological Research, 19:75-81.

[6] Alexander GG, Allan JD. 2007. Ecological success in stream restoration: Case studies from the Midwestern United States. Environmental Management, 40: 245-255.

[7] Weikai Bao, Qingheng Chen. The degraded processes and features of ecosystem. Chinese journal of ecology, 1999, 18(2):36-42.(in Chinese)

[8] Bo Li. The rangeland degradation in North China and its preventive Strategy. Scientia agricultura sinica, 1997, 30(6) :1-9.(in Chinese)

[9] Daily GC. Restoring value to the worlds degraded lands. Science, 1995, 269: 350 354.

[10]Jiaen Zhang, Qi Xu. The diagnostic features of degraded ecosystem and index systems for degradation evaluation. Resources and environment in the Yangtze Basin, 1999, 8(2): 215-220.(in Chinese)

[11]Jiaen Zhang, Qi Xu. Major issues in restoration ecology researches. Chines journal of applied ecology, 999, 10(1): 109- 113.(in Chinese)

[12] Jackson LL. Lopoukine D, Hillyard D. Ecological restoration: a definition and comments. Restoration Ecology, 1995, 3(2): 71-75.

[13]Juren Jiao. The main points of the ecological restoration and thinking. Soil and Water Conservation of China,2003, (2):1-2. (in Chinese)

[14]Qixing Zhou, Shuhe Wei, Qieru Zhang, et al. ecological restoration. Beijing: China Environmental Science Press, 2006: 50-100.(in Chinese)

[15]Hobbs R.J., Norton D.A. Towards a conceptual framework for restoration ecology. Restoration Ecology, 1996, 4: 93-110.

[16]Reay SD, Norton DA. Assessing the success of restoration plantings in a temperate New Zealand forest. Restoration Ecology, 1999, 7: 298-308. 